\title{
Photochemistry of Allenyl Salicylaldehydes
}

\author{
Frédéric Birbaum, ${ }^{\dagger}$ Antonia Neels, ${ }^{\ddagger}$ and Christian G. Bochet ${ }^{\star, \dagger}$ \\ Department of Chemistry, University of Fribourg, Chemin du Musée 9, CH-1700 \\ Fribourg, Switzerland, and Institut de Microtechnique, University of Neuchâtel, \\ Jacquet-Droz 1, CH-2002 Neuchâtel, Switzerland
}

christian.bochet@unifr.ch<smiles></smiles>

1<smiles>[R]C=C1C2=[Bi]C=CC=C2C2OCC1O2</smiles>

3

The intramolecular photocycloaddition of aryl aldehydes containing allene side chains is a versatile reaction as it provides a rapid and efficient access to original complex structures such as 1,3,4-tetrahydro-1,4-epoxy-5-alkylidene-2-benzoxepines 2 and substituted 2-oxa-tricyclo[5.2.2.0] $]^{1,5}$ undeca4,8,10-triene-9-carbaldehydes 3 . Novel polycyclic structures are characterized, and optimized strategies for the synthesis of the substrates 1 are described.

Creating complexity by the formation of new cores, stereocenters, and strained rings in one step from simple precursors is one of the many challenges of organic chemistry. Photochemistry is particularly attractive from this perspective because it may provide access to polycyclic structures without the need of aggressive reagents such as oxidants, reductants, acids, and bases. Tandem photocycloaddition/ fragmentation reactions and their applications in synthesis have been widely reviewed, but there is still a considerable potential for discovery. ${ }^{1}$ In the past few years, we have been interested in the formation of unusual ring systems. The 1,4cycloaddition of alkenes with arenes (para cycloaddition) has been well documented, but the similar process with allenes is much less understood. Our interest has focused on the photochemical reactivity of aryl aldehydes containing

\footnotetext{
University of Fribourg.

* University of Neuchâtel.
}

an allene side chain. In particular, when the substrate contains an aldehyde, the competition with a Paternò-Büchi-type reaction has to be considered. We report here the photochemical reactivity of ortho-allenyl benzaldehydes.

For this purpose, we prepared the $o$-allenyl-benzaldehyde $\mathbf{6 a}-\mathbf{f}$ substrates (Scheme 1) following a strategy described

(1) For reviews on photocycloaddition reactions, see: (a) Hoffmann, N. In Synthetic Organic Photochemistry; Griesbeck, A. G., ; Mattay, J., Eds.; Marcel Dekker, 2005; Vol. 12, pp 529-552. (b) Sieburth, S. McN. In Synthetic Organic Photochemistry; Griesbeck, A. G., ; Mattay, J., Eds.; Marcel Dekker, 2005; Vol. 12, pp 239-237. (c) Margaretha, P. In Synthetic Organic Photochemistry; Griesbeck, A. G., ; Mattay, J., Eds.; Marcel Dekker, 2005; Vol. 12, pp 211-237. (d) Fleming, S. A. In Synthetic Organic Photochemistry; Griesbeck, A. G., ; Mattay, J., Eds.; Marcel Dekker, 2005; Vol. 12, pp 141-160. (e) Griesbeck, A. G. In Synthetic Organic Photochemistry; Griesbeck, A. G., ; Mattay, J., Eds.; Marcel Dekker, 2005; Vol. 12, pp 89-139. (f) Horspool, W. M. Photochemistry 1999, 30, 119-148. (g) Bach, T. Synthesis 1998, 5, 683-703. (h) Winkler, J. D.; Bowen, C. M.; Liotta, F. Chem. Rev. 1995, 95, 2003-2020. (i) Wender, P. A.; Siggel, L.; Nuss, J. M. Org. Photochem. 1989, 10, 357-473. (k) Oppolzer, W. Acc. Chem. Res. 1982, 15, 135-141. 
Scheme 1. Synthesis of the Precursors $6 \mathbf{a}-\mathbf{f}$

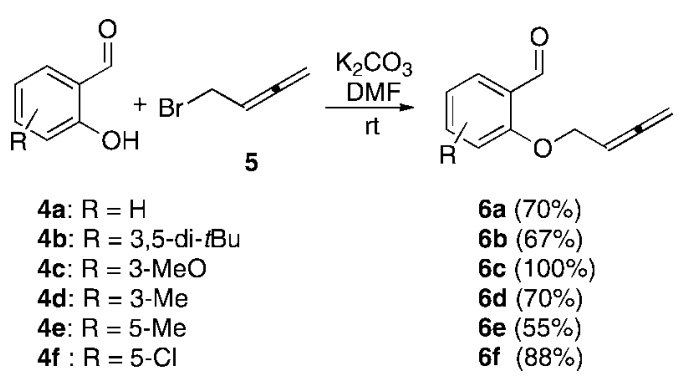

by Molander et al. ${ }^{2}$ Thus, simple nucleophilic substitution of allenyl bromide with a series of substituted salicylaldehydes gave $\mathbf{6 a}-\mathbf{f}$ in moderate to excellent yields $(60-100 \%)$. A variety of electron-withdrawing and electron-releasing groups were chosen to study the electronic requirements of the photocycloaddition.

The substituted allene $\mathbf{1 1}$ was also synthesized to examine the influence of a terminal substituent. For this substrate, the convergence point is much earlier, the methylallenyl unit being introduced by a two-step sequence. Thus, alkylation of the acetylide with acetaldehyde was followed by a Myerstype allenylation (Scheme 2). ${ }^{3}$

Scheme 2. Synthesis of a Terminally Substituted Allenyloxybenzaldehyde

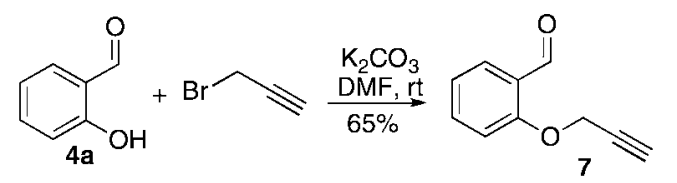<smiles>C#CCOc1cc(C(C)(C)C)ccc1C1OCCO1</smiles>

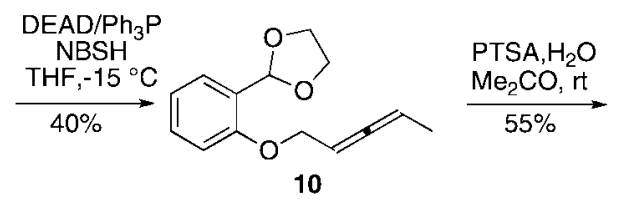<smiles>CC=CCCOc1ccccc1C=O</smiles>

11

Previous studies of intermolecular photochemical cycloadditions of carbonyl compounds with allenes giving strained 2-alkylideneoxetanes have been published. ${ }^{4}$ The proposed

(2) Molander, G. A.; Cormier, E. P. J. Org. Chem. 2005, 70, 26222626.

(3) Myers, A. G.; Zheng, B. J. Am. Chem. Soc. 1996, 118, 4492-4493. mechanism involves the addition of carbonyl triplets to the allenes. ${ }^{5}$ A limited range of allenes were used, and further reaction to give dioxaspiroheptanes is common. ${ }^{6}$ An important issue with alkylideneoxetanes is their sensitivity with respect to the purification conditions. They are unstable toward distillation, silica gel, Florisil, and even neutral alumina. Hydrolysis in aqueous acid gives back the original aldehyde and the ketone that is formally derived by the addition of water to the allene. On this basis, we expected to obtain 2-alkylideneoxetanes by intramolecular photocycloadditions between allenes and aromatic aldehydes or their decomposition products.

We first attempted the intramolecular photocycloaddition with 2-buta-2,3-dienyloxy-benzaldehyde 6a (Scheme 3).

Scheme 3. Effect of Substituents on the Regioselectivity of the Photocycloaddition
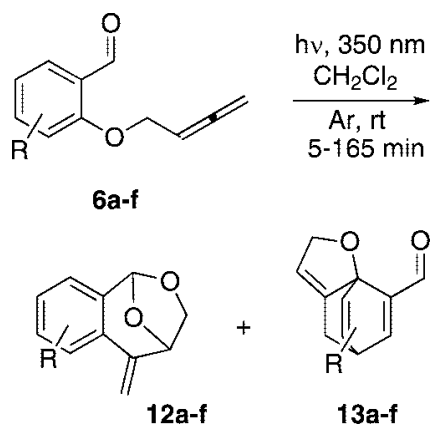

Surprisingly, irradiation of $\mathbf{6 a}$ at room temperature in dichloromethane did not lead to the expected 2-methyleneoxetane, but rather to a mixture of 1,3,4-tetrahydro-1,4epoxy-5-alkylidene-2-benzoxepine 12a (28\%) and 2-oxatricyclo[5.2.2.0 $]^{1,5}$ undeca-4,8,10-triene-9-carbaldehyde 13a $(48 \%)$. Obviously, more complex reaction pathways have to be considered.

Typical conditions for the reaction are the irradiation of a $10^{-2} \mathrm{M}$ solution in dichloromethane at room temperature (350 nm, Rayonet Photochemical Reactor). When the reaction is carried out at $-70{ }^{\circ} \mathrm{C}$ for $90 \mathrm{~min}$, the yield of 12a decreases $(10 \%)$ but has little influence on the formation of the bicyclo[2.2.2] octane derivative 13a (42\%).

Compared to the unsubstituted arene $\mathbf{6 a}$, electron-releasing groups slightly favor the 1,4-adduct $\mathbf{1 3}$ at the $\mathrm{C}-3$ position (Table 1, entries 3 and 4), more at the C-5 position (entry 5 ), and even make the reaction fully regioselective with two groups (entry 2). An electron-withdrawing group at the C-5 position slightly reverses the ratio.

(4) (a) Arnold, D.; Glick, A. J. Chem. Soc., Chem. Commun. 1966, 81, 3-814. (b) Gotthardt, H.; Steinmetz, R.; Hammond, G. S J. Org. Chem. 1968, 33, 2774-2780. (c) Gotthardt, H.; Hammond, G. S Chem. Ber. 1974, 107, 3922-3927. (d) Hudrlik, P. F.; Hudrlik, A. M.; Wan, C.-N. J. Org. Chem. 1975, 40, 1116-1120. (e) Gandhi, R. P.; Ishar, M. P. S. Tetrahedron. 1991, 47, 2211-2220.

(5) Gotthardt, H.; Steinmetz, R.; Hammond, G. S. J. Org. Chem. 1968, $33,2774-2779$. 7249 . 
Table 1. Effect of Substituents on the Regioselectivity of the Photocycloaddition

\begin{tabular}{clrcccc}
\hline & & time & & & \\
entry & \multicolumn{1}{c}{ substrate } & {$[\mathrm{min}]$} & & {$[\%]^{a}$} & {$[4+2]$} & {$[\%]$} \\
\hline 1 & $\mathbf{6 a}, \mathrm{R}=\mathrm{H}$ & 90 & $\mathbf{1 2 a}$ & 28 & $\mathbf{1 3 a}$ & 48 \\
2 & $\mathbf{6 b}, \mathrm{R}=3,5-\mathrm{di}^{t} \mathrm{Bu}$ & 5 & $\mathbf{1 2 b}$ & - & $\mathbf{1 3 b}$ & 94 \\
3 & $\mathbf{6 c}, \mathrm{R}=3-\mathrm{OCH}_{3}$ & 30 & $\mathbf{1 2 c}$ & 23 & $\mathbf{1 3 c}$ & 57 \\
4 & $\mathbf{6 d}, \mathrm{R}=3-\mathrm{CH}_{3}$ & 160 & $\mathbf{1 2 d}$ & 36 & $\mathbf{1 3 d}$ & 46 \\
5 & $\mathbf{6 e}, \mathrm{R}=5-\mathrm{CH}_{3}$ & 165 & $\mathbf{1 2 e}$ & 22 & $\mathbf{1 3 e}$ & 65 \\
6 & $\mathbf{6 f}, \mathrm{R}=5-\mathrm{Cl}$ & 120 & $\mathbf{1 2 f}$ & 44 & $\mathbf{1 3 f}$ & 31
\end{tabular}

${ }^{a}$ Yields determined by GC.

The structures have been established by NMR techniques $\left({ }^{1} \mathrm{H},{ }^{13} \mathrm{C} \text {, DEPT, COSY, and HETCOR sequences }\right)^{7}$ and confirmed by $\mathrm{X}$-ray analysis on benzoxepine $12 \mathrm{~d}$ and bicyclo[2.2.2] octane derivative 13b (Figure 1).
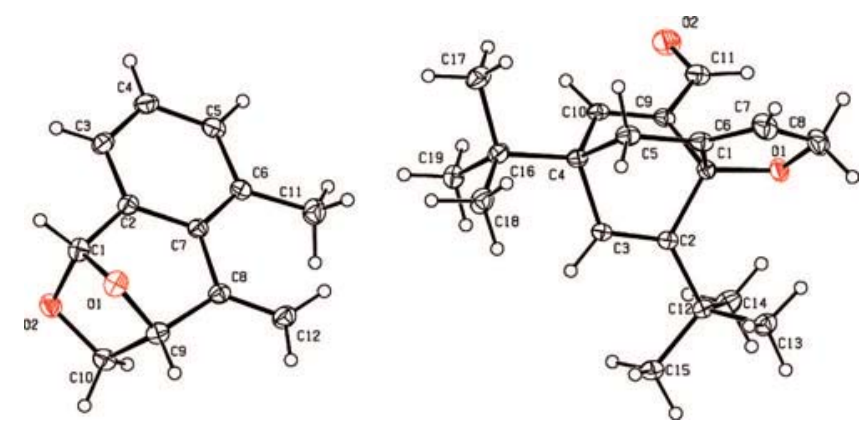

Figure 1. X-ray structure of $\mathbf{1 2 d}$ and $\mathbf{1 3 b}$.

The presence of a methyl group on the terminal part of the allene increases the yield of the formation of the benzoxepine, but the corresponding bicyclo[2.2.2]octane derivative is not observed. Thus, irradiation of 2-penta-2,3dienyloxy-benzaldehyde $\mathbf{1 1}$ ( $\mathrm{rt}, \mathrm{CH}_{2} \mathrm{Cl}_{2}, 350 \mathrm{~nm}$, Scheme 4)

Scheme 4. Irradiation of 2-Penta-2,3-dienyloxy-benzaldehyde

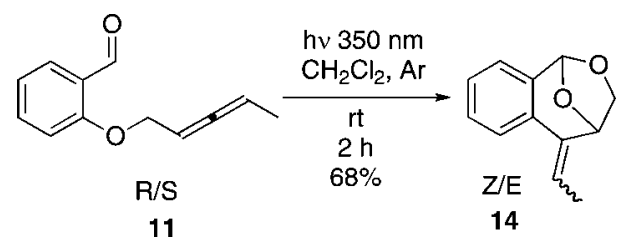

affords the benzoxepine $\mathbf{1 4}$ in $68 \%$ yield (GC). On the other hand, when the aldehyde $\mathbf{6 b}$ is reduced into the corresponding alcohol, no photocycloaddition is observed.

(7) The ${ }^{1} \mathrm{H}$ NMR spectrum of an epoxy benzoxepine is described in: Arcoleo, A.; Fontana, G.; Giammona, S.; Curcio, S. L.; Marino, M. L. Chem. Ind. 1977, 455.
The $Z$ and $E$ products are not formed at the same rate. However, after $2 \mathrm{~h}$ of irradiation of 11, isomerization and/ or selective degradation of the products gives an apparent stationary ratio of $Z$ and $E$ isomers of $1: 1 .^{8}$

To verify the photochemical nature of the processes, the $o$-allenyl-benzaldehydes were refluxed in dichloromethane over a period of $24 \mathrm{~h}$. NMR analysis only showed the starting compounds. Likewise, the starting allene 6a is stable upon heating up to $170{ }^{\circ} \mathrm{C}$ under microwave irradiation. Above $200^{\circ} \mathrm{C}$, decomposition is observed but without traces of any of the cycloadducts.

A reasonable mechanistic explanation for the formation of the benzoxepines 12 and 14 would be a sequence of intramolecular formal hetero Diels-Alder followed by an oxygen-tocarbon formal 1,3-sigmatropic migration. The thermal 1,3oxygen-to-carbon rearrangement (requiring temperatures as high as $130-160^{\circ} \mathrm{C}$ ) and the photochemical rearrangement involving a singlet excited-state have been both described earlier. ${ }^{9}$ This rearrangement is facilitated by the formation of aromatic products such as benzoxepines $\mathbf{1 2}$ and $\mathbf{1 4}$.

The formation of the bicyclo[2.2.2] octanes $\mathbf{1 3}$ might occur through a formal $[4+2]$ photocycloaddition or para photocycloaddition mechanism for which the aldehyde plays a crucial role even if it is not the reacting species (Scheme 5). ${ }^{1 \mathrm{a}, 10}$ The reaction does not seem to be reversible: $\mathbf{1 3 b}$ is

Scheme 5. Plausible Mechanism for the Formation of Benzoxepine $\mathbf{1 2}$ and $\mathbf{1 3}$
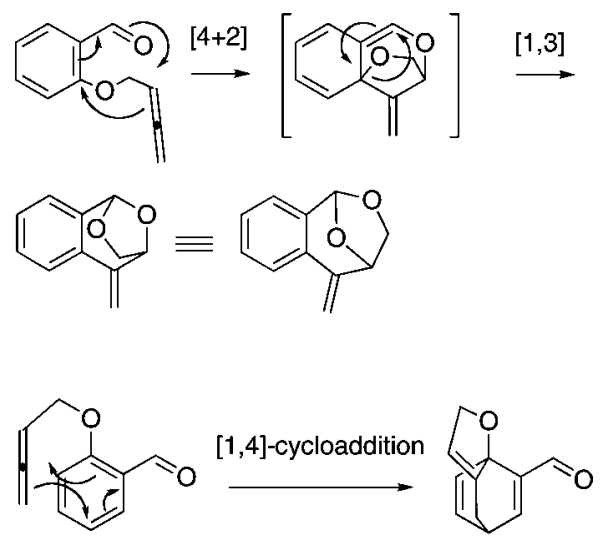

stable toward irradiation at $350 \mathrm{~nm}$ for $20 \mathrm{~min}$. At $300 \mathrm{~nm}$, ca. $50 \%$ degradation to an unidentified distribution of

(8) The reaction rate is followed by GC and shows the formation of both $Z$ and $E$ products. NMR analysis of the isolated compound shows a 1:1 mixture of $Z / E$ diastereomers.

(9) (a) Wang, S.; Callian, A.; Swenton, S. J J. Org. Chem. 1989, 54, 5364-5371. (b) Wang, S.; Callian, A.; Swenton, S. J. J. Org. Chem. 1990, $55,2272-2274$.

(10) (a) Hoffmann, N. In Synthetic Organic Photochemistry; Griesbeck, A. G., ; Mattay, J., Eds.; Marcel Dekker, 2005; Chap. 17, Vol. 12. For a review on photochemical cycloaddition between benzene derivates and alkenes, see: (b) Hoffman, N. Synthesis 2004, 4, 481-495. (c) Kishikawa, K.; Akimoto, S.; Kohmoto, S.; Yamamoto, M.; Yamada, K. J. Chem. Soc., Perkin Trans. 1 1997, 77. (d) Gilbert, A.; Taylor, G. N. J. Chem. Soc., Perkin Trans. 1 1980, 1761. (e) Gilbert, A.; Foulger, B. E.; Bryce-Smith, D. J. Chem. Soc., Chem. Commun. 1972, 664-665. 


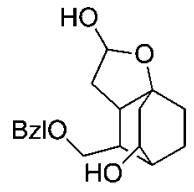

15

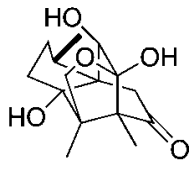

16
Figure 2. Related cores en route toward natural products.

products was observed after 20 min. Absorbance of $\mathbf{1 3 b}$ starts at $320 \mathrm{~nm}$.

Bicyclo[2.2.2] octane derivatives are versatile synthetic intermediates in total synthesis of natural products with a variety of types of carbon skeletons (Figure 2). For example, Yamada et al. described the formation of hemiacetal $\mathbf{1 5}$ in an 11-step sequence in the total synthesis of (-)- and (+)sanadaol. ${ }^{11,12}$ Likewise, to overcome the lack of effective and practical preparative methods for the synthesis of bicyclo[2.2.2] octane, Danishefsky et al. described an oxidative dearomatization-Diels-Alder cascade strategy to allow the assembly of the core structure of 11-O-debenzoyltashironin $16 .{ }^{13}$ The latter compound has been shown to promote neurite outgrowth.

It follows from this work that intramolecular photocycloadditions of $o$-allenyl-benzaldehyde efficiently build complex polycyclic 1,3,4-tetrahydro-1,4-epoxy-5-alkylidene- 2-benzoxepines and 2-oxa-tricyclo[5.2.2.0 $]^{1,5}$ undeca-4,8,10triene-9-carbaldehydes. On the other hand, $[2+2]$ photocycloaddition giving 2-alkylidene oxetane in the intermolecular version is not observed. It seems that the electronic density and the bulkiness of both aldehyde and allene could influence the regioselectivity of the photocycloaddition. Indeed, when the arene contains electron donor groups such as tert-butyl, only the para-photocycloaddition is observed, whereas a methyl group on the terminal part of the allene only gives the benzoxepine product. Further studies of this novel intramolecular photocycloaddition of ortho-allenylbenzaldehyde are ongoing.

Acknowledgment. Financial support of the Swiss National Science Foundation (grant 200020-109316) is gratefully acknowledged.

(11) Nagaoka, H.; Kobayashi, K.; Okamura, T.; Yamada, Y. Tetrahedron Lett. 1987, 6641-6644.

(12) Nagaoka, H.; Kobayashi, K.; Yamada, Y. Tetrahedron Lett. 1988, 46, 5945-5946.

(13) Cook, S. P.; Danishefsky, S. J. Org. Lett. 2006, 8, 5693-5695. 